\title{
Third-Order Quadrature Oscillator Circuit with Current and Voltage Outputs
}

\author{
Bhartendu Chaturvedi ${ }^{1}$ and Sudhanshu Maheshwari ${ }^{2}$ \\ ${ }^{1}$ Department of Electronics and Communication Engineering, Jaypee Institute of Information Technology, Noida 201304, India \\ ${ }^{2}$ Department of Electronics Engineering, Z. H. College of Engineering and Technology, Aligarh Muslim University, \\ Aligarh 202002, India
}

Correspondence should be addressed to Bhartendu Chaturvedi; bhartendu.prof@gmail.com

Received 9 July 2013; Accepted 12 August 2013

Academic Editors: C. W. Chiou, H. L. Hartnagel, and E. Tlelo-Cuautle

Copyright ( 2013 B. Chaturvedi and S. Maheshwari. This is an open access article distributed under the Creative Commons Attribution License, which permits unrestricted use, distribution, and reproduction in any medium, provided the original work is properly cited.

\begin{abstract}
The paper presents a new quadrature oscillator of third order which can provide four quadrature current outputs and two quadrature voltage outputs. The new circuit employs three differential voltage current conveyors and six passive components, most of which are in grounded form. Circuit operation at high frequencies is verified along with nonideality and parasitic study. The circuit enhancement for generation of four phase clock waveforms is also given. The proposed circuit is a novel addition to the oscillator family.
\end{abstract}

\section{Introduction}

Realization of quadrature oscillators using current mode active building blocks has received continuous attention ever since the advent of current conveyors. The literature has thus witnessed voluminous works which may run into an equally voluminous bibliography, which is beyond the scope of the present discussion and hence limited to some selected works of the last few decades [1-10]. Differential voltage current conveyor became popular in the late 1990s and continued to find applications in realizing oscillators till recently [1117]. Besides the realization of multiphase oscillators, thirdorder quadrature oscillators found special attention owing to their low-distortion output generation capability [18-24]. As a result, numerous high performance oscillator circuits continue to find most recent space in the literature [25-29].

In this paper a new third-order quadrature oscillator based on DVCCs is proposed. The proposed circuit requires three DVCCs, three grounded capacitors, and three resistors, of which two are grounded. The circuit generates four quadrature current outputs at high impedance nodes and two quadrature voltage outputs. The circuit usability at high frequencies with low THD is demonstrated. The nonideal analysis as well as parasitic analysis is included to study the real world performance of the proposed circuit. The new proposal further enriches the subject area. Section 2 presents the actual circuit description. Section 3 is devoted to the nonideal analysis. Parasitics considerations are given in Section 4. Simulation results are given in Section 5. Application of the proposed circuit is further explored in Section 6. Lastly, Section 7 presents conclusion of the paper.

\section{Proposed Circuit}

2.1. Circuits' Description. The symbol and CMOS implementation of differential voltage current conveyor (DVCC) are shown in Figure 1. DVCC is a five-port building block and is characterized by the following port relationship:

$$
\begin{gathered}
V_{X}=V_{Y_{1}}-V_{Y_{2}}, \\
I_{Y_{1}}=I_{Y_{2}}=0, \\
I_{Z_{+}}=+I_{X}, \\
I_{Z_{-}}=-I_{X} .
\end{gathered}
$$

In a DVCC, terminals $Y_{1}, Y_{2}$ exhibit infinite input impedance. Thus no current flows in terminal $Y_{1}, Y_{2}$. The terminal $X$ 


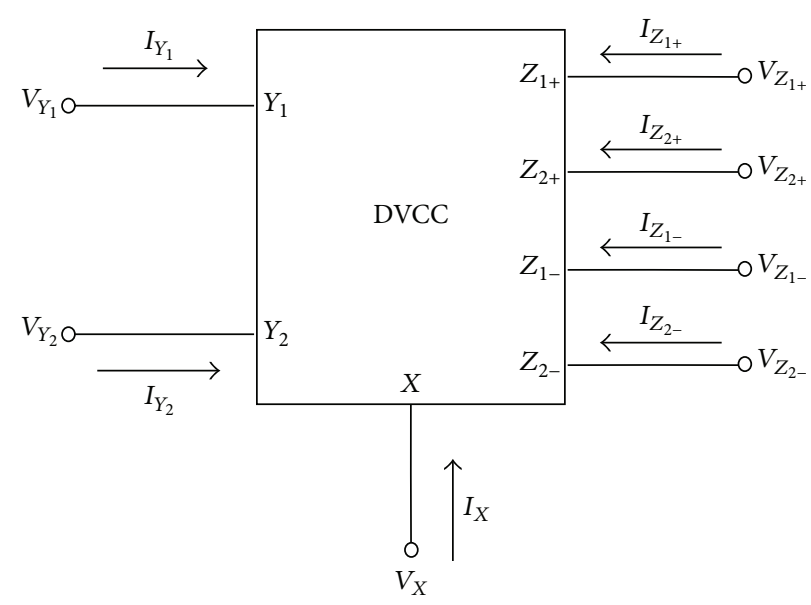

(a)

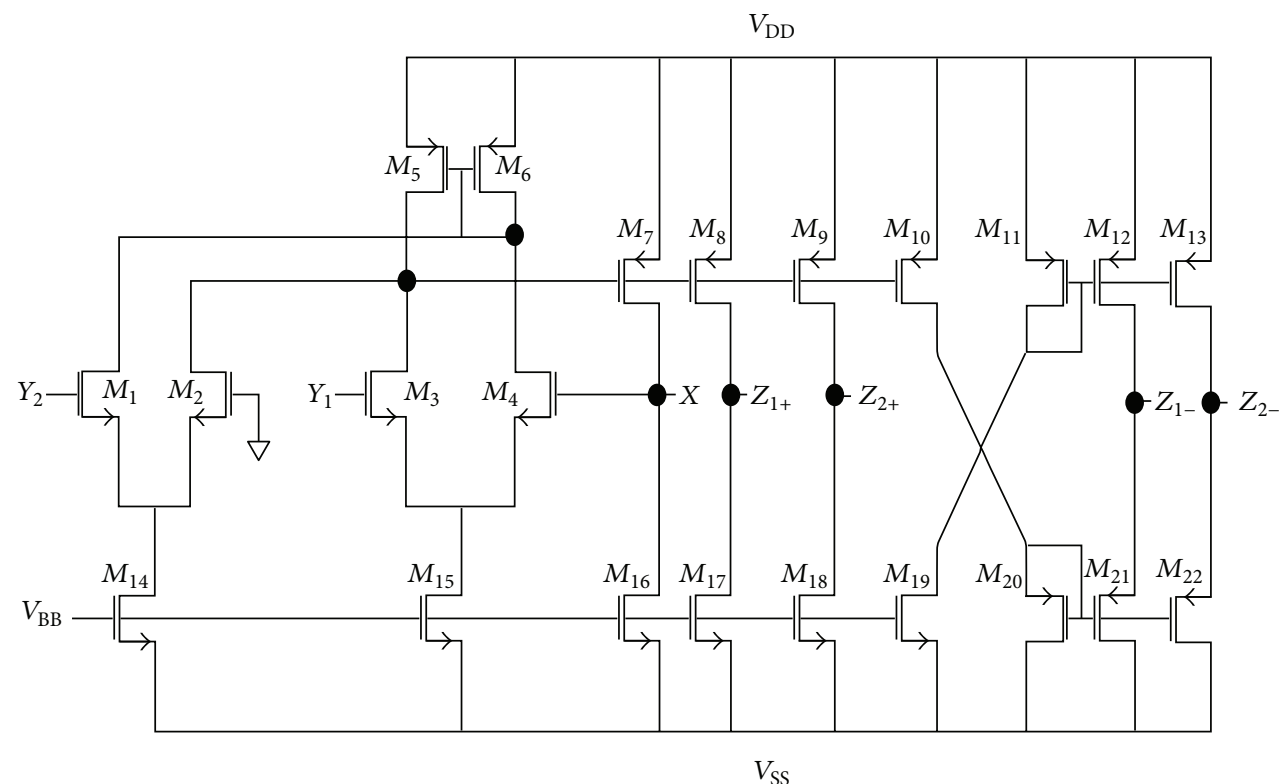

(b)

FIGURE 1: (a) Symbol of DVCC. (b) CMOS implementation of DVCC.

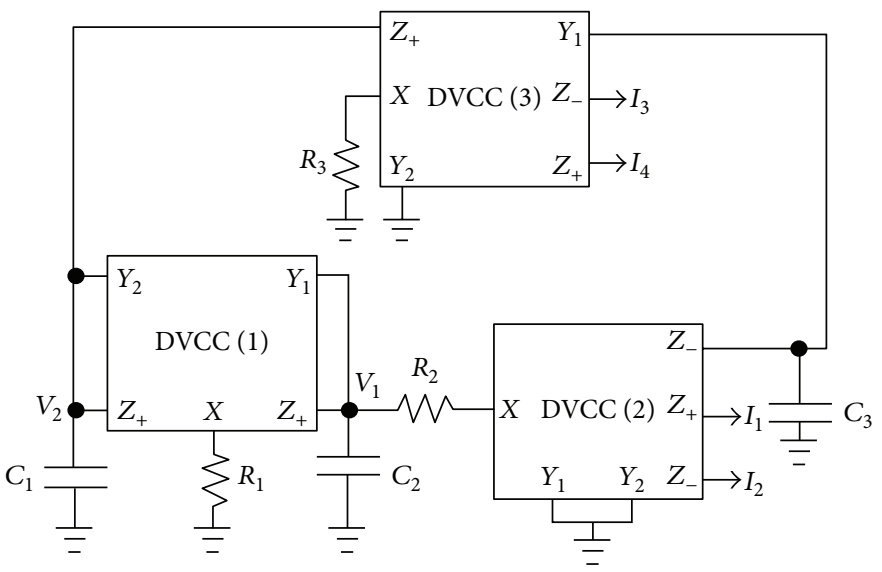

FIGURE 2: Proposed circuit of third-order voltage/current mode quadrature oscillator. 


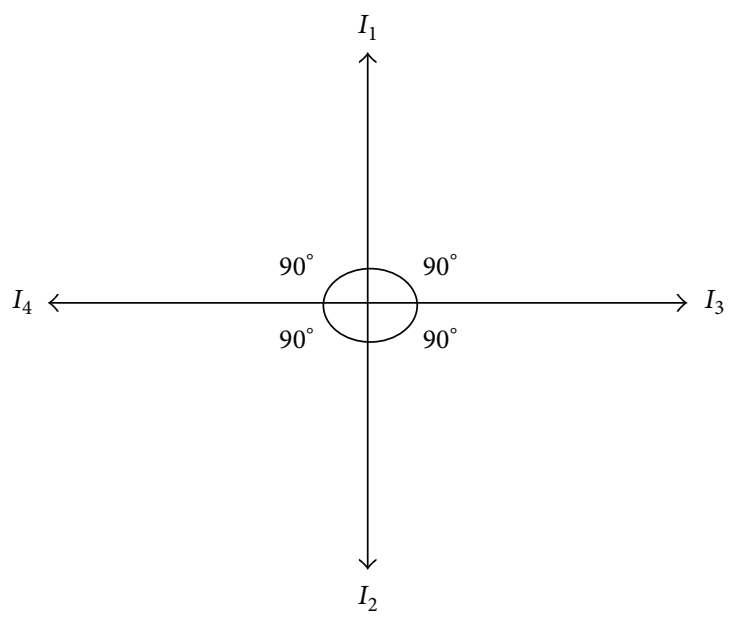

(a)

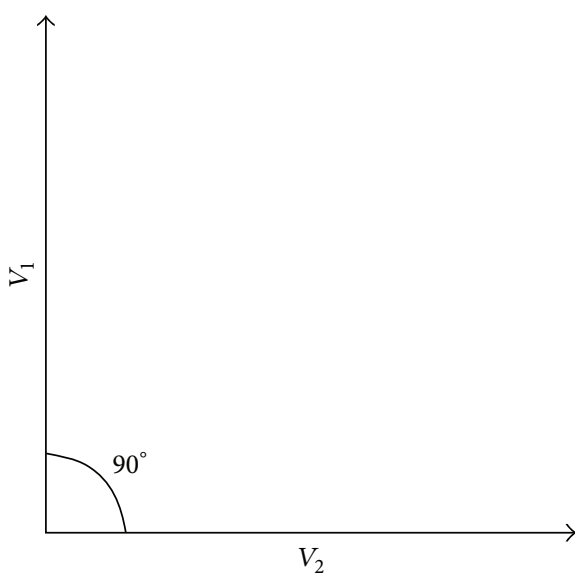

(b)

Figure 3: (a) Phasor diagram depicting quadrature current outputs. (b) Phasor diagram depicting quadrature voltage outputs.

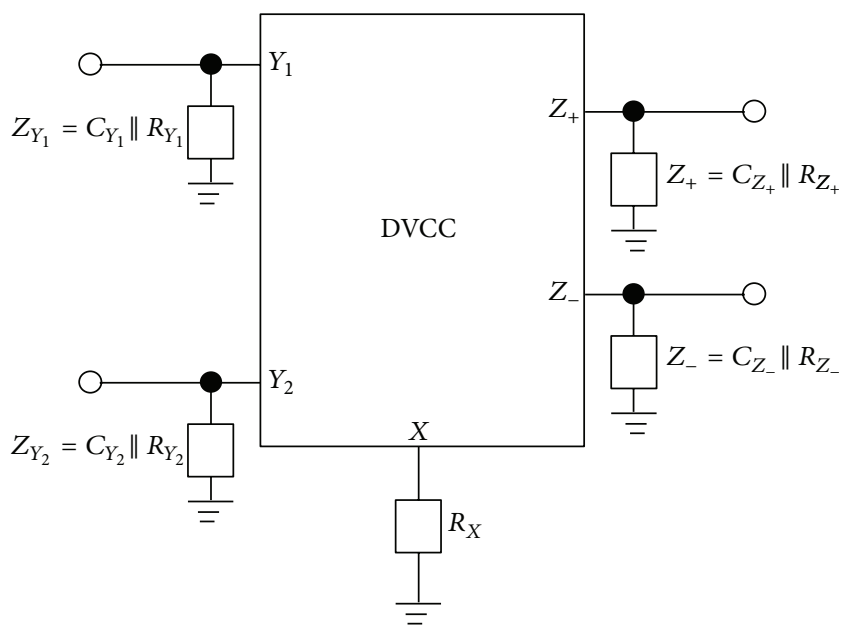

FIgure 4: Parasitic model of DVCC.

exhibits zero input impedance. The $Z_{+}$and $Z_{-}$terminals exhibit high output impedance. The proposed circuit of third order quadrature oscillator is shown in Figure 2. It is composed of three DVCCs, three grounded capacitors, and three resistors.

The characteristic equation of the circuit can be expressed as

$$
\begin{aligned}
s^{3}+ & s^{2} \frac{\left(C_{2} R_{2}+C_{1} R_{1}-C_{1} R_{2}\right)}{C_{1} C_{2} R_{1} R_{2}}+s \frac{1}{C_{1} C_{2} R_{1} R_{2}} \\
& +\frac{1}{C_{1} C_{2} C_{3} R_{1} R_{2} R_{3}}=0 .
\end{aligned}
$$

Replacing $s$ with $j \omega$ and equating real and imaginary terms, the above equation yields the frequency of oscillation (FO) and condition of oscillation (CO) as

$$
\begin{gathered}
\text { FO: } f_{0}=\frac{1}{2 \Pi \sqrt{C_{1} C_{2} R_{1} R_{2}}}, \\
\text { CO: } C_{1} C_{2} R_{1} R_{2}=C_{3} R_{3}\left(C_{2} R_{2}+C_{1} R_{1}-C_{1} R_{2}\right) .
\end{gathered}
$$

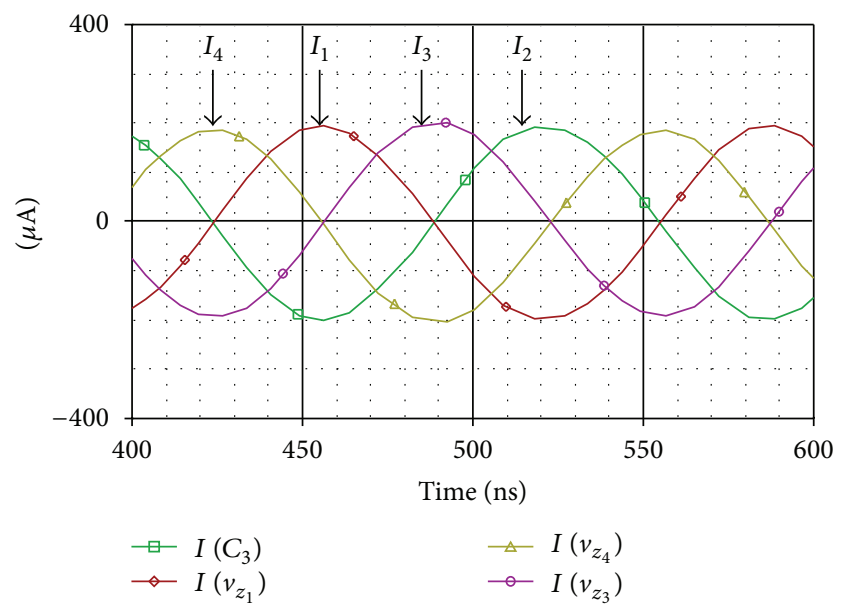

FIGURE 5: Quadrature current output waveforms.

Assuming equal value resistors $\left(R_{1}=R_{2}=R\right)$ and capacitors $\left(C_{1}=C_{2}=C\right)$, the expressions of (3) and (4) are simplified to

$$
\begin{aligned}
& \text { FO: } f_{0}=\frac{1}{2 \Pi R C} \text {, } \\
& \text { CO: } C R=C_{3} R_{3} .
\end{aligned}
$$

The various voltage and current outputs depicted in Figure 3 are related as

$$
\begin{gathered}
V_{2}=-\left(j \omega C_{2} R_{1}\right) V_{1}, \\
I_{1}=\left(j \omega C_{3} R_{3}\right) I_{3}, \\
I_{2}=\left(j \omega C_{3} R_{3}\right) I_{4}, \\
I_{1}=-I_{2}, \\
I_{3}=-I_{4} .
\end{gathered}
$$




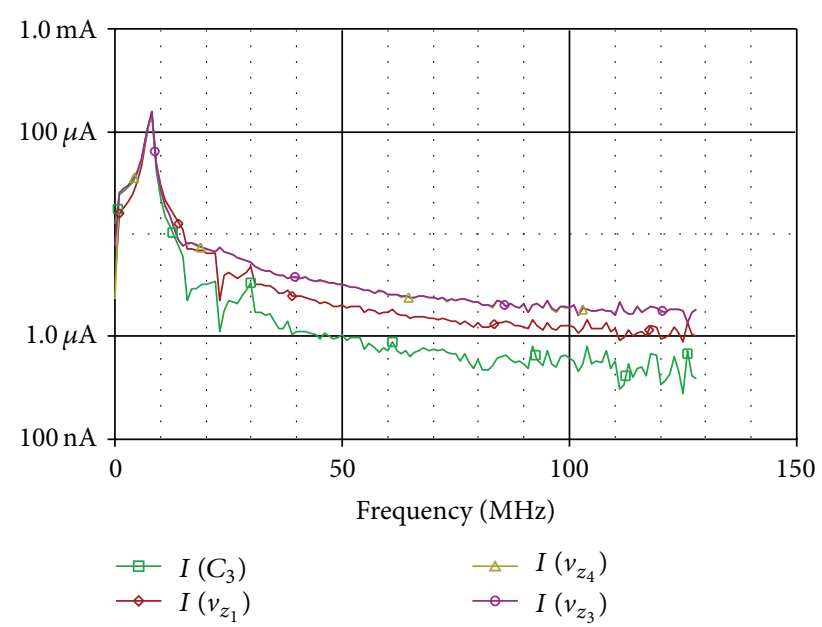

FIGURE 6: Frequency spectrum of current outputs.

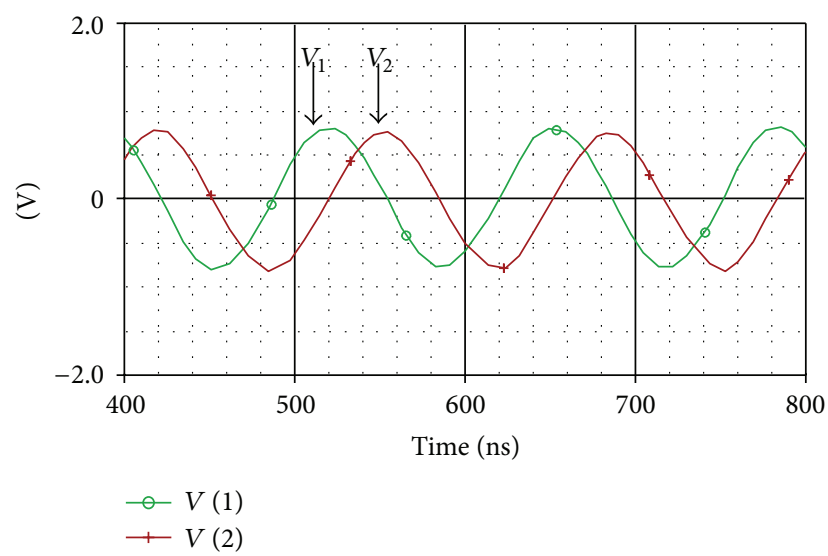

FIGURE 7: Quadrature voltage output waveforms.

It is evident from (6) that two quadrature voltages in the forms of $V_{1}$ and $V_{2}$ with a phase shift of $90^{\circ}$ are obtained. It is quite worth noting that the voltage outputs unlike the available current outputs do not appear at appropriate (low) impedance level. The four current outputs are available at desired high impedance level and also exhibit a quadrature relationship. Four quadrature current outputs in the forms of $I_{1}, I_{2}, I_{3}$ and $I_{4}$ with a progressive phase shift of $90^{\circ}$ are obtained. The various outputs generated have equal amplitudes. The sensitivity figures of FO with respect to passive components are low and given in

$$
s_{C_{1}, C_{2}, R_{1}, R_{2}}^{f_{0}}=-\frac{1}{2} \text {. }
$$

Equation (7) shows that the sensitivity figures for the proposed circuit are found to be less than unity, which implies good sensitivity performance.

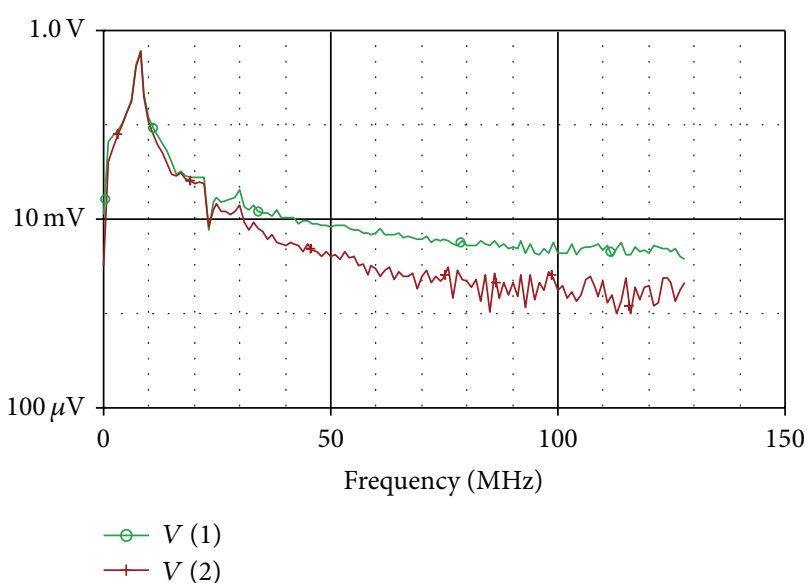

FIGURE 8: Frequency spectrum of voltage outputs.

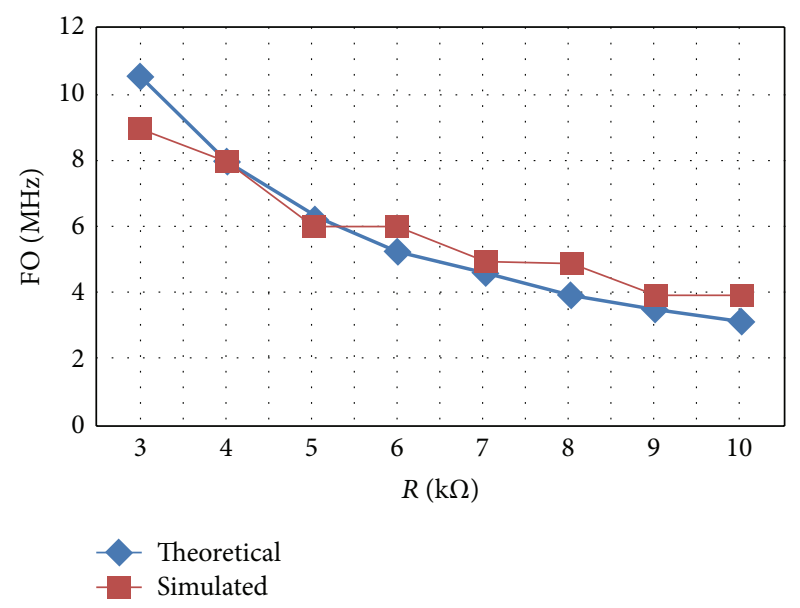

FIGURE 9: Frequency of oscillation variation with $R$ (for $R_{1}=R_{2}=$ $R)$.

\section{Nonideal Analysis}

Taking the nonidealities of the DVCC into account, the relationship between the terminal voltages and currents of the DVCC can be rewritten as:

$$
\begin{gathered}
V_{X}=\beta_{1} V_{Y_{1}}-\beta_{2} V_{Y_{2}}, \\
I_{Y_{1}}=I_{Y_{2}}=0, \\
I_{Z+}=+\alpha I_{X}, \\
I_{Z-}=-\alpha I_{X} .
\end{gathered}
$$

Here, $\beta_{1}$ and $\beta_{2}$ are the voltage transfer gains from $Y_{1}$ and $Y_{2}$ terminals, respectively, to the $X$ terminal. And $\alpha$ is the current transfer gain from $X$ terminal to $Z+$ and $Z$ - terminals. The above transfer gains deviate unity by the voltage and current transfer errors, which are quite small and technology dependent. Moreover, the transfer gains, instead of being real, are actually frequency dependent with an upper bound on the usable frequency. 
TABLE 1: Model parameters used for simulation.

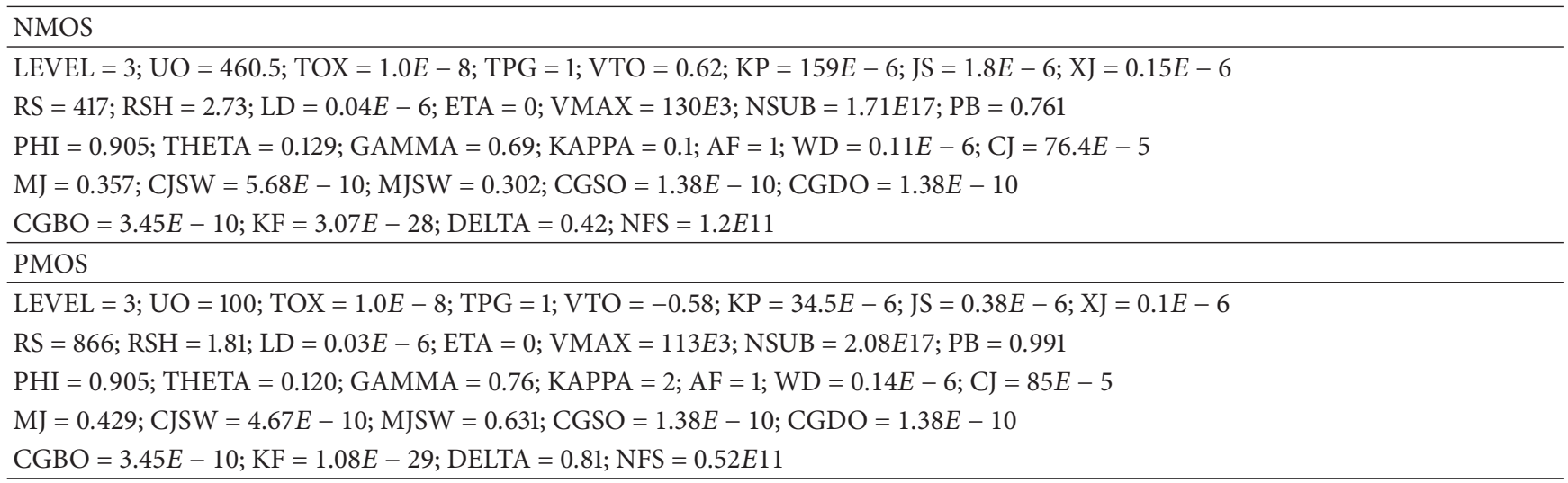

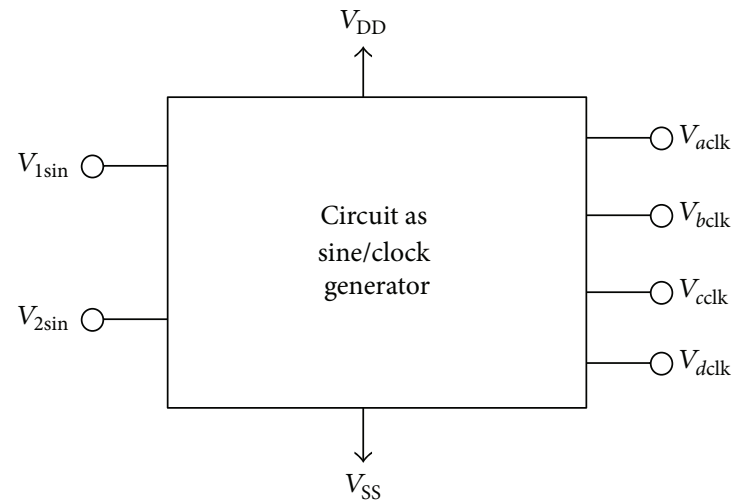

FIgURE 10: Proposed circuit as sine/clock generator.

The third-order quadrature oscillator of Figure 2 is reanalyzed using (8) so as to obtain the characteristic equation as:

$$
\begin{aligned}
s^{3}+ & s^{2} \frac{\left(\alpha_{1} \beta_{12} C_{2} R_{2}+C_{1} R_{1}-\alpha_{1} \beta_{11} C_{1} R_{2}\right)}{C_{1} C_{2} R_{1} R_{2}} \\
& +s \frac{\alpha_{1} \beta_{12}}{C_{1} C_{2} R_{1} R_{2}}+\frac{\alpha_{1} \alpha_{2} \alpha_{3} \beta_{12} \beta_{31}}{C_{1} C_{2} C_{3} R_{1} R_{2} R_{3}}=0 .
\end{aligned}
$$

The modified frequency of oscillation and condition of oscillation are

$$
\begin{gathered}
\text { FO: } f_{0}=\frac{1}{2 \Pi} \sqrt{\frac{\alpha_{1} \beta_{12}}{C_{1} C_{2} R_{1} R_{2}}}, \\
\text { CO: } \alpha_{2} \alpha_{3} \beta_{31} C_{1} C_{2} R_{1} R_{2} \\
=C_{3} R_{3}\left(\alpha_{1} \beta_{12} C_{2} R_{2}+C_{1} R_{1}-\alpha_{1} \beta_{12} C_{1} R_{2}\right) .
\end{gathered}
$$

Here, $\beta_{11}, \beta_{12}$ are the voltage transfer gains from $Y_{1}, Y_{2}$ terminals, respectively to the $X$ terminal of $\mathrm{DVCC}_{1}$, and $\beta_{31}$ is the voltage transfer gain from $Y_{1}$ terminal to the $X$ terminal of $\mathrm{DVCC}_{3} . \alpha_{1}$ is the current transfer gain from the $X$ terminal to $Z_{+}$terminal of $\mathrm{DVCC}_{1}, \alpha_{2}$ is the current transfer gain from the $X$ terminal to $Z_{-}$terminal of $\mathrm{DVCC}_{2}$ and $\alpha_{3}$ is the current transfer gain from the $X$ terminal to $Z_{+}$terminal of $\mathrm{DVCC}_{3}$.
TABle 2: Dimensions of MOS transistors used in DVCC of Figure $1(\mathrm{~b})$.

\begin{tabular}{lc}
\hline Transistors & $W(\mu \mathrm{m}) / L(\mu \mathrm{m})$ \\
\hline$M_{1}, M_{2}, M_{3}, M_{4}$ & $1.6 / 1$ \\
$M_{5}, M_{6}$ & $8 / 1$ \\
$M_{13}, M_{14}$ & $29 / 1$ \\
$M_{7}, M_{8}$ & $20 / 1$ \\
$M_{15}, M_{16}$ & $90 / 1$ \\
$M_{9}, M_{10}, M_{11}, M_{12}$ & $60 / 1$ \\
$M_{17}, M_{18}, M_{19}, M_{20}$ & $270 / 1$ \\
\hline
\end{tabular}

It is to be noted that (10) reduces to (3) and (11) reduces to (4) for the ideal value of the transfer gains, which is equal to unity. The active and passive sensitivities are given in

$$
s_{\alpha_{1}, \beta_{12}}^{f_{0}}=-s_{C_{1}, C_{2}, R_{1}, R_{2}}^{f_{0}}=\frac{1}{2} .
$$

The sensitivities of active and passive components are within unity in magnitude. Thus, the new circuit of third-order quadrature oscillator enjoys attractive active and passive sensitivity performances. It can be further observed from (10) and (11) that the non-idealities slightly change the frequency of oscillation and condition of oscillation.

\section{Parasitic Considerations}

The various parasitics involved with a typical current conveyor [30] are well known. Like the second-generation current conveyor (CCII), the DVCC has a small parasitic resistance $R_{X}$ at port $X$, high input impedance $\left(R_{Y} / / C_{Y}\right)$ at port $Y$, and high input impedance $\left(R_{Z_{+}} / / C_{Z_{+}}\right)$at $Z+$ terminal. The parasitic model of DVCC is shown in Figure 4 . As the $X$ terminal of the $\mathrm{DVCC}_{1}, \mathrm{DVCC}_{2}$, and $\mathrm{DVCC}_{3}$ is connected to a resistor, the parasitic resistance at the $X$ terminal of the $\operatorname{DVCC}\left(R_{X}\right)$ can be absorbed as a part of the main resistance. As the value of $R_{X_{1}}, R_{X_{2}}$, and $R_{X_{3}}$ is much smaller than that of, the external resistors, frequency of oscillation of the proposed circuit of third-order quadrature oscillator will be slightly affected. The effects of the capacitors at ports $Y$ and $Z$ of the DVCC are also negligible because these capacitors 
TABLE 3: \% THD for current and voltage outputs.

\begin{tabular}{lll}
\hline Outputs & $I_{1}$ & $I_{2}$ \\
\hline \% THD & 1.82 & 1.16 \\
\hline
\end{tabular}

$\square(13)$

(a)

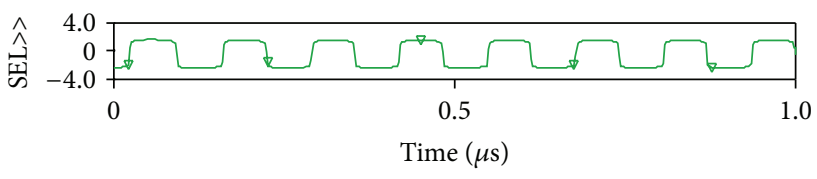

$\nabla V(11)$

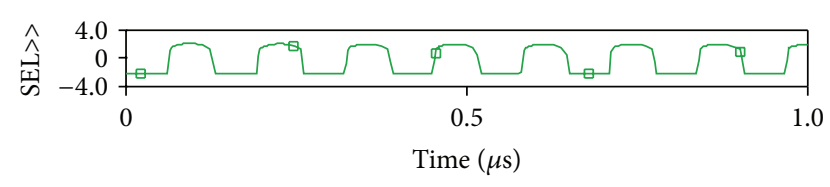

$\square(10)$

(b)

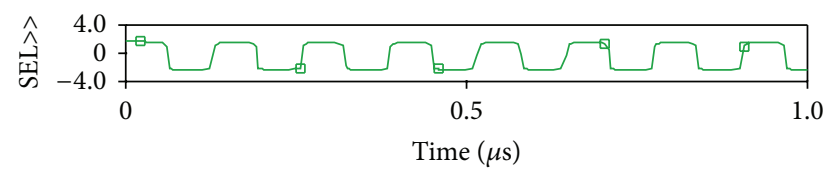

$\square V(9)$

(d)

FIGURE 11: Four phase clock wave shapes.

are quite small (and process dependent) as compared to the external capacitors. However, the proposed circuit of quadrature oscillator is reanalyzed taking into account the above parasitic effects. A reanalysis of the proposed circuit of quadrature oscillator yields

$$
s^{3} a+s^{2} b+s c+d=0
$$

where

$$
\begin{aligned}
& a=R^{\prime} R^{\prime \prime} R^{\prime \prime \prime} R_{1}^{\prime 2} R_{2}^{\prime} R_{3}^{\prime}\left(C_{1}+C^{\prime}\right)\left(C_{2}+C^{\prime \prime}\right)\left(C_{3}+C^{\prime \prime \prime}\right) \\
& \times\left[R_{2}^{\prime} R_{2}^{\prime \prime} R_{1}^{\prime}\left(C_{1}+C^{\prime}\right)\left(C_{2}+C^{\prime \prime}\right)\right. \\
& +R^{\prime \prime} R^{\prime \prime \prime} R_{1}^{\prime}\left(C_{2}+C^{\prime \prime}\right)\left(C_{3}+C^{\prime \prime \prime}\right)+R^{\prime} R^{\prime \prime \prime} R_{1}^{\prime} \\
& \times\left(C_{1}+C^{\prime}\right)\left(C_{3}+C^{\prime \prime \prime}\right)+R^{\prime} R^{\prime \prime} R^{\prime \prime \prime} \\
& \left.\times\left(C_{2}+C^{\prime \prime}\right)\left(C_{3}+C^{\prime \prime \prime}\right)\right] \\
& +R^{\prime} R^{\prime \prime \prime} R_{3}^{\prime}\left[R^{\prime \prime} R_{1}^{\prime 2}\left(C_{1}+C^{\prime}\right)\left(C_{3}+C^{\prime \prime \prime}\right)\right. \\
& \left.\quad+R_{2}^{\prime}\left(C_{1}+C^{\prime}\right)\left(C_{3}+C^{\prime \prime \prime}\right)\right] \\
& \times R_{1}^{\prime} R_{2}^{\prime} R_{3}^{\prime} \quad \times R_{1}^{\prime}\left(C_{1}+C^{\prime}\right)+R^{\prime \prime} R_{1}^{\prime}\left(C_{2}+C^{\prime \prime}\right) \\
& +R^{\prime \prime \prime} R_{1}^{\prime}\left(C_{3}+C^{\prime \prime \prime}\right)+R^{\prime} R^{\prime \prime}\left(C_{1}+C^{\prime}\right) \\
& +R^{\prime} R^{\prime \prime}\left(C_{2}+C^{\prime \prime}\right)+R^{\prime} R^{\prime \prime \prime}\left(C_{3}+C^{\prime \prime \prime}\right) \\
& \left.+R^{\prime \prime} R^{\prime \prime \prime}\left(C_{3}+C^{\prime \prime \prime}\right)\right] \\
& \left.\times\left(R_{3}^{\prime}+C^{\prime \prime \prime}\right)+R^{\prime} R^{\prime \prime \prime}\left(C_{3}+C^{\prime \prime \prime}\right)\right]
\end{aligned}
$$

$$
\begin{aligned}
d=R_{1}^{\prime}[ & R^{\prime \prime} R_{1}^{\prime} R_{3}^{\prime}+R_{1}^{\prime} R_{2}^{\prime} R_{3}^{\prime} \\
& +R^{\prime} R^{\prime \prime} R_{3}^{\prime}+R^{\prime} R_{2}^{\prime} R_{3}^{\prime} \\
& \left.+R^{\prime} R^{\prime \prime} R^{\prime \prime \prime}+R^{\prime \prime} R_{2}^{\prime} R_{3}^{\prime}\right],
\end{aligned}
$$

where $R^{\prime}=R_{Z_{1+}}+R_{Y_{12}}+R_{Z_{3+}}, R^{\prime \prime}=R_{Z_{1+}}+R_{Y_{11}}, R^{\prime \prime \prime}=$ $R_{Z_{2-}}+R_{Y_{31}}$ and $R_{1}^{\prime}=R_{1}+R_{X_{1}}, R_{2}^{\prime}=R_{2}+R_{X_{2}}, R_{3}^{\prime}=R_{3}+R_{X_{3}}$, and $C^{\prime}=C_{Z_{1+}}+C_{Y_{12}}+C_{Z_{3+}}, C^{\prime \prime}=C_{Z_{1+}}+C_{Y_{11}}, C^{\prime \prime \prime}=C_{Z_{2-}}+C_{Y_{31}}$.

From (13) it is clear that the parasitic resistances and capacitances appear in shunt with external capacitors, which are connected at $Z$ terminals, thus ensuring a possibility of predistorting the designed values. Therefore it is to be concluded that the circuits are not adversely affected by the parasitic resistances and capacitances. Moreover, from (13), it can be further observed that the parasitic resistances/capacitances merge with the external value. Such a merge does cause slight deviation in circuit's parameters, which can be eliminated by predistorting the element values to be used in the circuit.

\section{Simulation Results}

The proposed third-order quadrature oscillator was next simulated using PSPICE, an industry standard tool for evaluating the performance of circuits. The CMOS implementation of DVCC in Figure 1(b) was used with $0.5 \mu \mathrm{m}$ CMOS parameters and aspect ratios as listed in Tables 1 and 2, respectively, and the supply voltages were $V_{\mathrm{DD}}=-V_{\mathrm{SS}}=2.5 \mathrm{~V}$. The biasing voltage $V_{\mathrm{BB}}$ was taken as $-1.4 \mathrm{~V}$. The circuit was designed using equal capacitors and resistors of values $C_{1}=C_{2}=C_{3}=$ $5 \mathrm{pF}$ and, $R_{1}=R_{2}=R_{3}=4 \mathrm{k} \Omega$. The theoretical FO using this design was $7.96 \mathrm{MHz}$. The simulated FO was found to be $7.94 \mathrm{MHz}$, which is very close to the theoretical value and only 
$0.25 \%$ in error. The results for the four current outputs and two voltage outputs are shown in Figures 5 and 7 respectively. The Fourier spectrum of the outputs of Figures 5 and 7, are shown in Figures 6 and 8, respectively. The THD at various outputs is listed in Table 3. A low THD along with good accuracy of the FO is a justifying feature for the third-order oscillator. To further support the circuit's practical utility, $R$ (for $R_{1}=R_{2}=R$ ) was varied so as to vary the FO. The FO tuning through $R$ is shown in Figure 9. The FO is found to vary from $3.18 \mathrm{MHz}$ to $10.62 \mathrm{MHz}$ for variation of $R$ from $10 \mathrm{~K} \Omega$ to $3 \mathrm{~K} \Omega$, respectively. Both theoretical and simulated FO are found to be closely matched; the discrepancy in simulated frequency being the result of various nonidealities and parasitics as discussed in Sections 3 and 4.

\section{Circuit Enhancement}

Next, a new application of the proposed third-order quadrature oscillator in clock generation is given. A four phase clock $\left(V_{a c l k}, V_{b c l k}, V_{c c l k}\right.$ and $\left.V_{d c l k}\right)$ along with two sine waveforms $\left(V_{1 \sin }\right.$ and $\left.V_{2 \sin }\right)$ is generated by using the proposed circuit of oscillator (Figure 2). The block diagram representation is shown in Figure 10. For generation of four phase clocks, four voltage outputs are taken instead of four current outputs (as shown in Figure 2) at the $Z$ terminals of $\mathrm{DVCC}_{2}$ and $\mathrm{DVCC}_{3}$. The four phase clock voltage outputs are at a progressive phase shift of $90^{\circ}$. Note that the $Z$ terminals exhibit a high output resistance, sufficient to saturate the DVCCs. The output levels depend on the supply voltage $\left(V_{\mathrm{DD}}\right.$ and $\left.V_{\mathrm{SS}}\right)$. No additional resistors are being used, and thus the new scheme is compatible with monolithic implementation. The results of the four phase clock are shown in Figure 11 and very well justify this new application.

\section{Conclusion}

A new third-order quadrature oscillator circuit based on three DVCCs as active element, three grounded capacitors, and three resistors is presented. The circuit provides both quadrature voltage and current outputs. The circuit exhibits good high frequency performance. The enhancement of the proposed circuit as sine/clock generator is further given. PSPICE simulations using $0.5 \mu \mathrm{m}$ CMOS parameters support the validity and practical utility of the proposed circuit.

\section{Acknowledgment}

The authors thank Academic Editors for recommending this paper. The paper was submitted at the time when article processing charges for the Journal were waived off.

\section{References}

[1] A. S. Sedra and K. C. Smith, "A second generation current conveyor and its applications," IEEE Transactions on Circuit Theory, vol. 17, no. 1, pp. 132-134, 1970.

[2] B. Wilson, "Recent developments in current conveyors and current-mode circuits," IEE Proceedings G, vol. 137, no. 2, pp. 63-77, 1990.
[3] A. M. Soliman, "Simple sinusoidal RC oscillators using current conveyors," International Journal of Electronics, vol. 42, pp. 309311, 1975.

[4] R. Senani, "New canonic single resistor controlled oscillator using a single current conveyor," Electronics Letters, vol. 15, no. 18, pp. 568-569, 1979.

[5] A. M. Soliman, "Two integrator loop quadrature oscillators: a review," Journal of Advance Research, vol. 4, no. 1, pp. 1-11, 2013.

[6] S. Maheshwari and M. S. Ansari, "Catalog of realizations for DXCCII using commercially available ICs and applications," Radioengineering, vol. 21, pp. 281-289, 2012.

[7] G. Souliotis and C. Psychalinos, "Harmonic oscillators realized using current amplifiers and grounded capacitors," International Journal of Circuit Theory and Applications, vol. 35, no. 2, pp. 93-104, 2007.

[8] S. S. Gupta, R. K. Sharma, D. R. Bhaskar, and R. Senani, "Sinusoidal oscillators with explicit current output employing current-feedback op-amps," International Journal of Circuit Theory and Applications, vol. 38, no. 2, pp. 131-147, 2010.

[9] A. U. Keskin and D. Biolek, "Current mode quadrature oscillator using current differencing transconductance amplifiers (CDTA)," IEE Proceedings, vol. 153, no. 3, pp. 214-218, 2006.

[10] D. Biolek, A. U. Keskin, and V. Biolkova, "Quadrature oscillator using CDTA-based integrators," WSEAS Transactions on Electronics, vol. 3, no. 9, pp. 463-469, 2006.

[11] H. O. Elwan and A. M. Soliman, "Novel CMOS differential voltage current conveyor and its applications," IEE Proceedings, vol. 144, pp. 856-860, 1997.

[12] W. Chiu, S. I. Liu, H. W. Tsao, and J. J. Chen, "CMOS differential difference current conveyors and their applications," IEE Proceedings, vol. 143, pp. 91-96, 1996.

[13] S. S. Gupta and R. Senani, "Grounded-capacitor current-mode SRCO: novel application of DVCCC," Electronics Letters, vol. 36, no. 3, pp. 195-196, 2000.

[14] S. S. Gupta and R. Senani, "Realisation of current-mode SRCOs using all grounded passive elements," Frequenz, vol. 57, no. 1-2, pp. 25-36, 2003.

[15] P. Kumar, A. U. Keskin, K. Pal, and V. Kumar, "DVCCbased single element controlled oscillators using all-grounded components and simultaneous current-voltage mode outputs," Frequenz, vol. 59, pp. 7-8, 2005.

[16] S. Maheshwari and B. Chaturvedi, "High output impedance CMQOs using DVCCs and grounded components," International Journal of Circuit Theory and Applications, vol. 39, no. 4, pp. 427-435, 2011.

[17] S. Maheshwari, "Quadrature oscillator using grounded components with current and voltage outputs," IET Circuits, Devices and Systems, vol. 3, no. 4, pp. 153-160, 2009.

[18] S. Maheshwari, "Current-mode third-order quadrature oscillator," IET Circuits, Devices and Systems, vol. 4, no. 3, pp. 188-195, 2010.

[19] J.-W. Horng, H. Lee, and J.-Y. Wu, "Electronically tunable thirdorder quadrature oscillator using CDTAs," Radioengineering, vol. 19, no. 2, pp. 326-330, 2010.

[20] M. T. Abuelma'Atti and M. A. Al-Qahtani, "A new currentcontrolled multiphase sinusoidal oscillator using translinear current conveyors," IEEE Transactions on Circuits and Systems II, vol. 45, no. 7, pp. 881-885, 1998.

[21] P. Prommee and K. Dejhan, "An integrable electronic-controlled quadrature sinusoidal oscillator using CMOS operational transconductance amplifier," International Journal of Electronics, vol. 89, no. 5, pp. 365-379, 2002. 
[22] S. Maheshwari and I. A. Khan, "Current controlled third order quadrature oscillator," IEE Proceedings, vol. 152, pp. 605-607, 2005.

[23] G. Souliotis and C. Psychalinos, "Electronically controlled multiphase sinusoidal oscillators using current amplifiers," International Journal of Circuit Theory and Applications, vol. 37, no. 1, pp. 43-52, 2009.

[24] I. A. Khan, P. Beg, and M. T. Ahmed, "First order current mode filters and multiphase sinusoidal oscillators using CMOS MOCCIIs," Arabian Journal for Science and Engineering, vol. 32, no. 2, pp. 119-126, 2007.

[25] J.-W. Horng, "Current/voltage-mode third order quadrature oscillator employing two multiple outputs CCIIs and grounded capacitors," Indian Journal of Pure and Applied Physics, vol. 49, no. 7, pp. 494-498, 2011.

[26] M. Kumngern and S. Junnapiya, "Current-mode third-order quadrature oscillator using minimum elements," in Proceedings of the International Conference on Electrical Engineering and Informatics (ICEEI '11), pp. 1-4, July 2011.

[27] M. Kumngern, P. Lamun, and K. Dejhan, "Current-mode quadrature oscillator using current differencing transconductance amplifiers," International Journal of Electronics, vol. 99, pp. 971-986, 2012.

[28] V. Biolková, J. Bajer, and D. Biolek, "Four-phase oscillators employing two active elements," Radioengineering, vol. 20, no. 1, pp. 334-339, 2011.

[29] T. Tsukutani, Y. Sumi, and Y. Fukui, "Electronically controlled current-mode oscillators using MO-OTAs and grounded capacitors," Frequenz, vol. 60, no. 11-12, pp. 220-223, 2006.

[30] C. Sanchez-Lopez, "Pathalogical equivalents of fully-differential active devices for symbolic nodal analysis," IEEE Transactions on Circuits and Systems-I, vol. 60, pp. 603-615, 2013. 

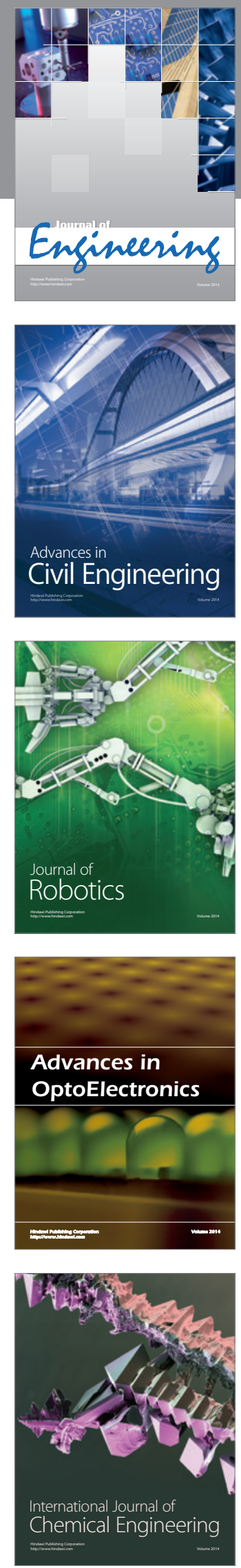

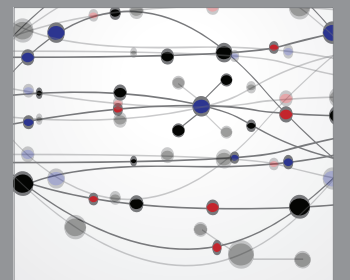

The Scientific World Journal
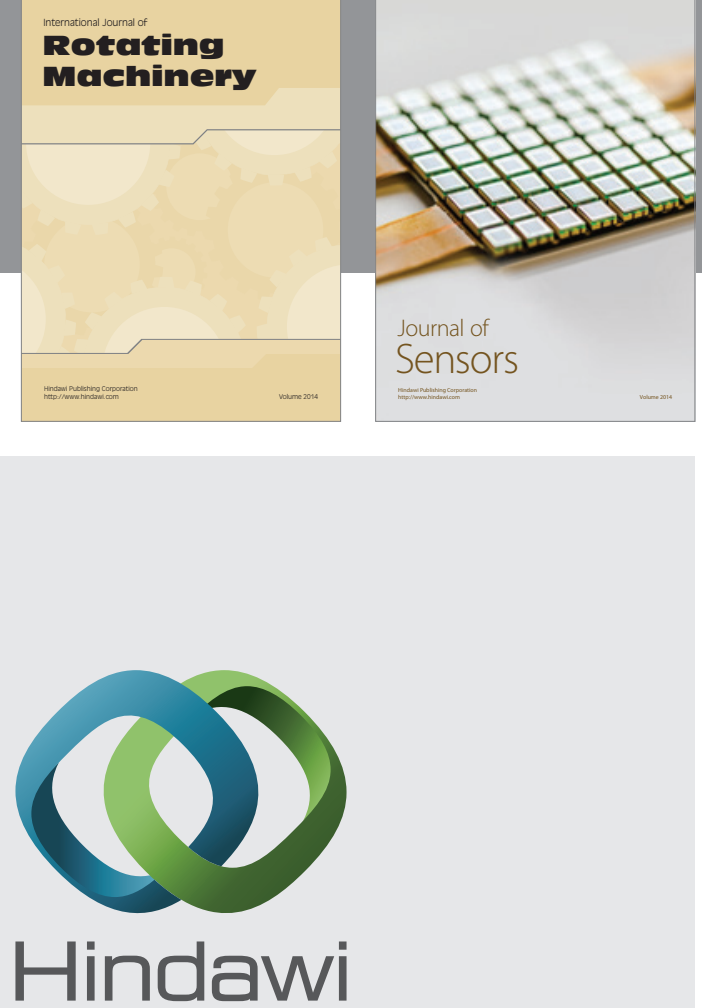

Submit your manuscripts at http://www.hindawi.com
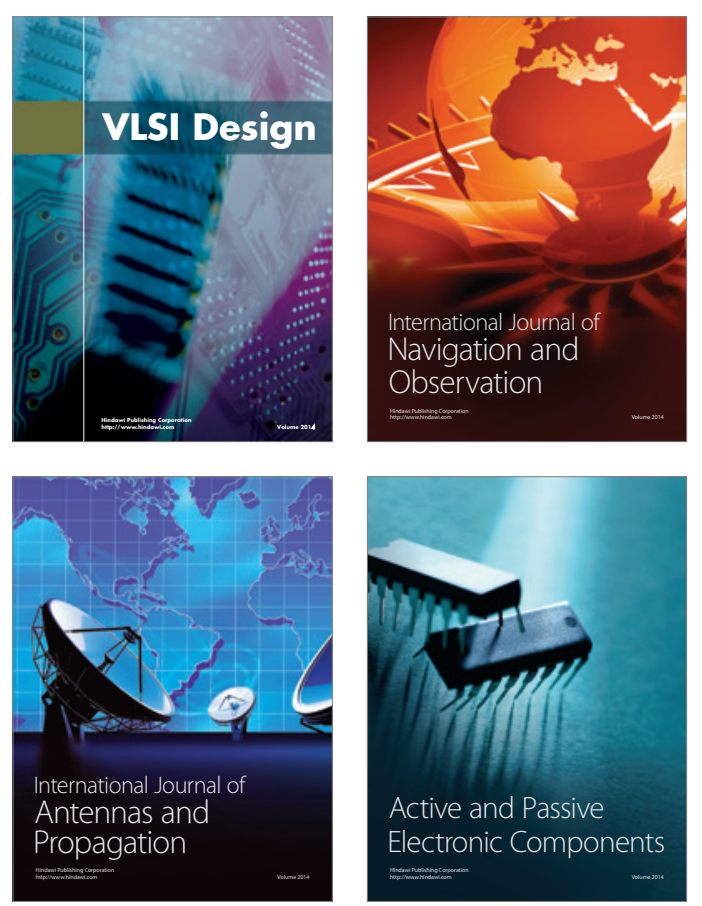
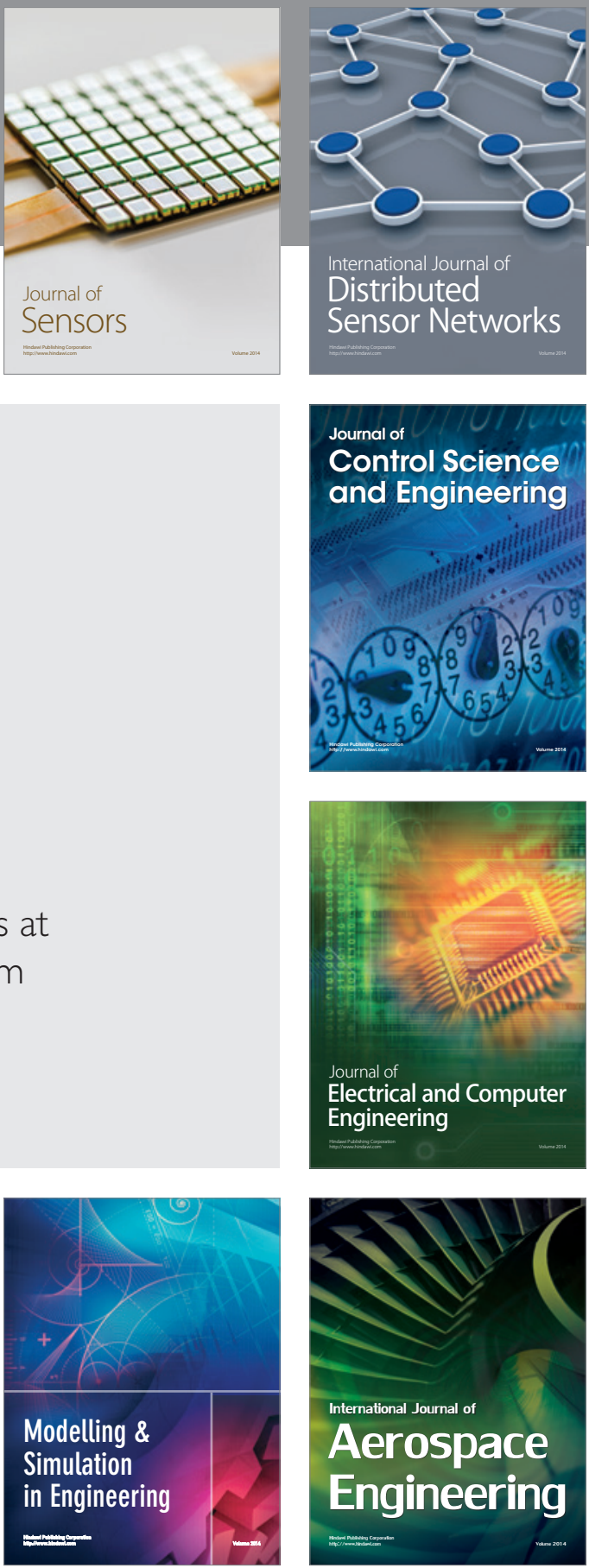

Journal of

Control Science

and Engineering
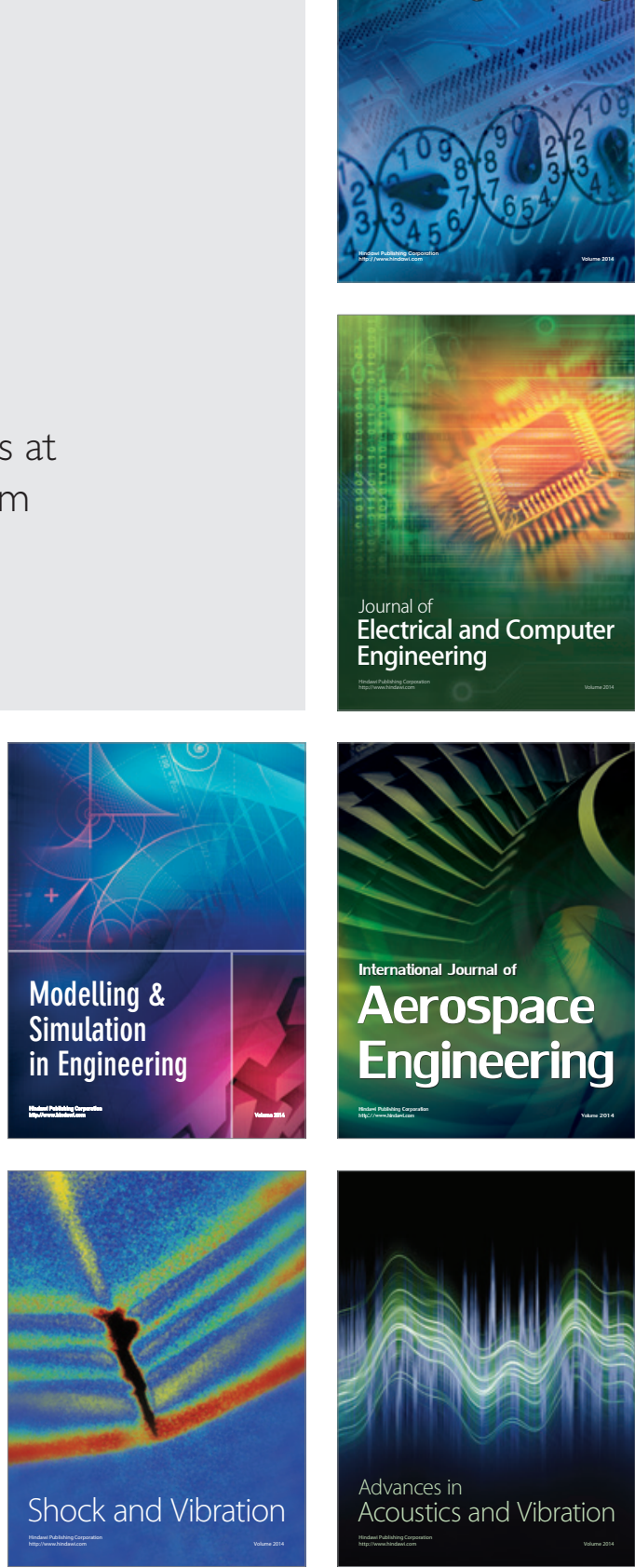